\title{
Empirical Study on Planning Participation in the Network Society ----The Case of No.55 Bus Event in Shanghai
}

\author{
Miaoxi ZHAO, Rongrong LI, Gaofeng XU \\ College of Architecture/State Key Laboratory of Subtropical Building Science, South China University of \\ Technology, Guangzhou 510640, China
}

\begin{abstract}
With the development of information technology, Internet can serve as a vital platform of planning participation, mostly because of the quick and timely feedback which enhances the efficiency of planning participation. This article selects No.55 Bus adjusting event as research case. After observing the process of network participation, we evaluate the public participation pattern of planning issues under background of network society on the basis of analyzing characteristics of network activity. The pattern of public planning participation in internet context, compared with traditional one, has considerable advantages, but the nature of network society also makes it some shortcomings at the same time. The existence of the virtual environment hinders localization effect. In order to solve this problem, this article puts forward some opinions and suggestions to enhance the supervision and supporting role to urban planning by network participation pattern.
\end{abstract}

KEYWORD: Network society; urban planning; public participation; No.55 Bus in Shanghai

\section{INTRODUCTION}

Since the birth of modern urban planning, heroism of architects has long been a dominant in the field of planning and design, which peaked in the 1930s. At that time, planners owned the absolute power in the field of urban planning. With the deep application of computer in 1970 s, rationalism of decision system become another main tool of planning. Thus, avoiding irrationality of market through regulation and management by government is the base point of planning policy. And the power of planners stemmed from the technology at that time. After the rise of new liberalism in $1980 \mathrm{~s}$, the social intervention effect of state and local governments relatively declined, making increasingly active social groups and citizens become important factors that affect decision-making (Voets, J. et al. 2007) [36]. The government's traditional tools of management are faced with the prominent difficulty (Albrechts, S. \& Mandelbaum, S. 2005) [1]. The focus of urban development then turned to planning process from planning products (Healey, P. 2003) [19]. As a result, communication and participation become

National Natural Science Foundation of China, No.51478189; State Key Laboratory of Subtropical Building Science, No.2013KB20;

Social Science of Guangdong Provence, No.2013GDYYS01 indispensable in urban planning (Innes, J. \& Booher, D. 1999) [21]. On the background above, stipulation and implementation of planning has to attach importance to cooperation among diversified subjects. How to recognize and organize the bottom up urban planning has become an important governance issue from then on.

Just as engineering technology, established status of minority elite in decision-making before 1970s, quickly spread of information technology, with the internet come into normal society from military and institutions, caused social and economic transformation globally, making traditional hierarchical authority gradually collapse. Castells, M. (1996) [7] put forward the point of the rise of network society and put it into regional development, industrial spatial organization and other social science categories. There existed a great deal of research in space of flow in the network society in the field of urban sociology and geography from then on. While from the content that academic concept of network society covers, social organization including urban planning is also an important issue. To explore the interaction process situation in the planning and design should become an important research issue in the network society (Verma, N. \& Shin, H. 2006) [35].

The network society, facilitated by the development of social network sites (SNSs), is 
gradually shaping and forming in China. Internetbased SNSs are have some common characteristics as communication platforms, such as public and semi-public forums and information sharing (Boyd, D. \& Ellison, N. 2007) [5]. Their important social function is that large-scale network can be used to perform powerful collective actions (Gordon, E. \& Manosevitch, E. 2011) [14].

Since the middle of 1990s, local governments in western countries are trying to promote information practice in the process of planning through new media and communication technology in local cities, for which receive multiple support of planners, urban development enterprises, communication agency and media organizations (Graham, S. \& Marvin, S. 1999) [15]. But series of cases' studying still focused on planning products as Healey, P. (1997) [17] mentioned that, cities and regions, in the influence of informatization, are focused just as spatial objects. The Internet and communication technology are also regarded as planning tools, while ignoring the complexity in urban planning formulation process under the background of network society. Thus, to cope with the development of Internet technology and discuss participation process of planning in the network society has great research significance, which is the main springboard of this article.

\section{URBAN PLANNING THEORY IN NETWORK SOCIETY}

From the perspective of Castells, M., the characteristics of the network society means the globalization of economic behaviors, the networking of organization forms, flexible ways of working and the polarization of occupation structure (Castells, M. 1996) [7]. According to Shiode, N. (1999) [33] and Kaneyasu, I. (1997) [22], urban planning, on the background of information technology, involves two aspects which are urban issues and planning issues. On urban issues, the influence of urban space in network society, regarded as planning product, could be summarized as two points, one is the urban space in the network context, that is the city and space under the expression and influence of Internet media. The other is network facility in real space, which means the universality of Internet infrastructure in city and region. On planning issues, the influence mentioned above could be summarized as three aspects. First, taking information technology as planning assistant system of decision-making directly, a typical example is the application of GIS in planning and design. Second one is the urban space planning in virtual network. Last one is the Planning participation process in network society.

This article selects Shanghai No.55 Bus line adjusting event as research case to explain the whole process from two aspects according this specific example. First one, on urban issue, is the space issue of Shanghai No.55 Bus on the expression and influence of Weibo. Second one, on planning issue, is the entire network participation process that Shanghai No.55 Bus line adjusting event solving. If summarize the case in one sentence, that is, the strong backlash from public in Weibo caused the attention of municipal officers and eventually shut down their planning of repealing of this bus line. But this rhetoric undoubtedly passed away as a forgotten news no matter to the professional planners that focus on planning process or to any ordinary people who have a little spy. As results, all sorts of stories and even whether argument is reasonable or not cannot obtain during the event itself. In consideration that there is little empirical study on planning process in China, especially in planning participation process under Internet regulation, this research reviewed on process characteristics of planning participation and sociality of urban space in the network society, through which to provide theoretical support for empirical study.

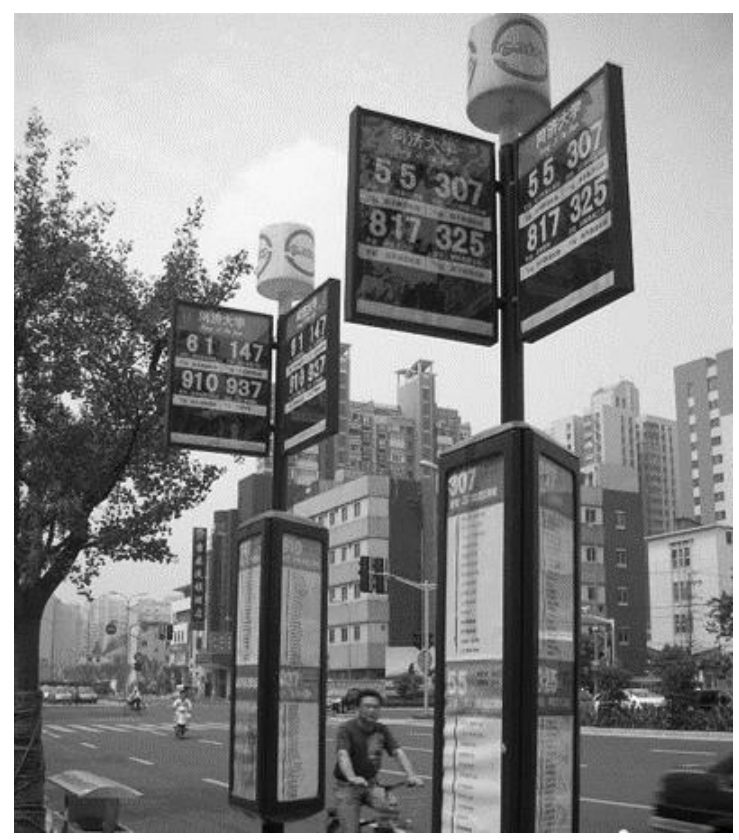

Figure 1. Picture of No.55 and No.910 Bus Station (from Baidu.com)

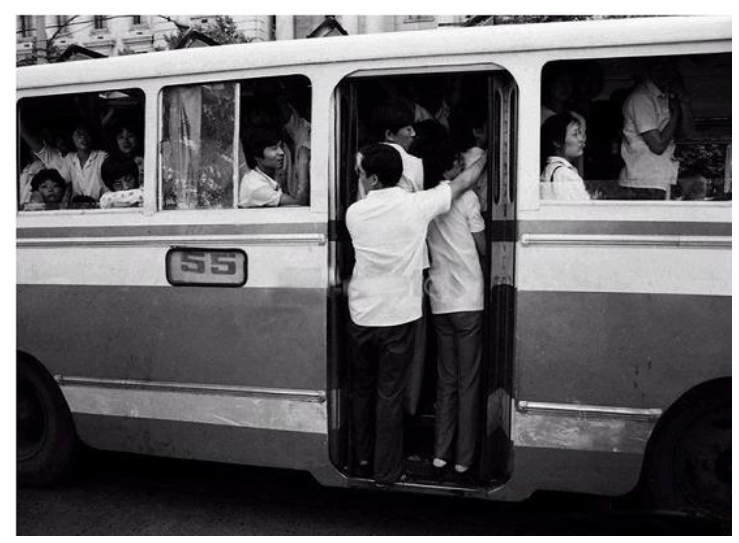

Figure 2. Picture of old No.55 Bus (from Baidu.com) 


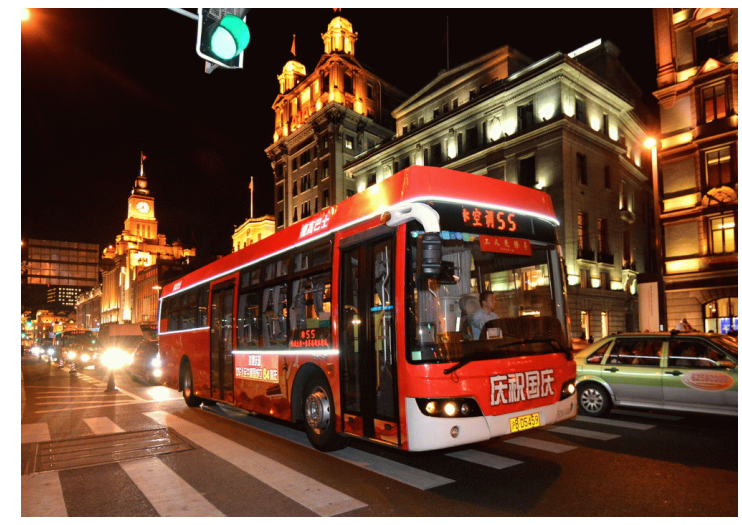

Figure 3. Picture of new No.55 Bus (from Baidu.com)

Entering the new century, based on theory of Castells, M. [8], Albrechts, S. and Mandelbaum, S. (2005) [1] examined the process and method of urban planning in the background of network society, and invited dozens of scholars to do theory summary of urban planning process under Internet including Graham, S. etc. (2005) [16]:the primary feature of network society is openness of social structure and decentralization (Castells, M. 1996) [7] with the color of the administrative hierarchy minimized and thus enhanced the participatory democracy (Albrechts, S. \& Mandelbaum, S. 2005) [1]. But Berry, L. (2004) put forward that, decisionmaking process in network society is not necessarily equal participation [3]. On the other hand, however, this decision-making process may contain negative effects, for such process would probably under manipulation of opinion leaders rather than promoted by real general public. Further, the lack of community-based nongovernmental organizations made it even more difficult for planners to represent the public or to engage with the grassroots concerns (Leaf, M. \& Hou, L. 2006) [24]. Besides, the digital divide is one of key challenges in the new media age (Castells, M. 1989) [6]: There are inequalities between different social groups in terms of access to, or knowledge of ICT. On the other side, the activity of network society act as increasingly bottom up organization form. The development of ICT technology makes face to face communication demand greatly reduced, led to the lower threshold space constraints, with less constraints by administrative boundaries and units during the process and communication in network society. At the same time, the urban social space form and physical structure more and more depend on multiple network connections with time - space dimension characteristic (Albrechts, S. \& Mandelbaum, S. 2005) [1].

At the same time when network society put forward by Castells, M.(1996) [7], Healey, P.(1997) [18] made the theory of "communication planning" in the field of urban planning. He indicated that the involvement and interaction of three key stakeholders (the economy, civil society, and the state) as well as place-focused governance are decisively successful to collaborative planning. Verma, N. and Shin, H. (2006) [35], based on the relevant theory of Habermas, tended to the consistency between the theory of Planning communication and network society to some extent. Cheng, Y. (2013) [12] argued that the incipient collaborative planning and public participation through the functions of internet in China hold an increasingly vital influence. She pointed out that grassroots participants, with mounting power, had significantly influenced urban planning practices and increased public's awareness of planning participation. Innes, J. and Booher, D. hold the opinion that the diversification and interdependency of actors are important role in the planning process (Booher, D. \& Innes, J. 2002 [4], Innes, J. \& Booher, D. 2010 [20]). From researches above, during public participation process in network society, interestrelated social groups not only have a direct link to the planning events, but has a close connection between them. Each participating individuals, due to the relative openness of medium, can observe the opinions of others, and express final opinion combined with his initial idea, which is one of the important characteristics in communication. That means, the opinions of the participants are not only related to its initial ideas, but also to the close relation of public opinion environment (the complexity of spread theory). Many actors, with the relationship between each other, constitute a decision network to some extent. Dempwolf, S. and Lyles, W.(2012) [34] even involved social network analysis (SNA) framework into planning process.

The changes of decision in urban planning are complementary to the public participation: on one hand, these changes themselves require extensive public participation. On the other hand, active public participation promote transformation from happening. With further development of Internet, the bottom-up approach of public participation in the planning process has been promoted by the spread of new media. For example, citizens in Nanjing used microblogs and city forums to oppose the establishment of trees to make way for a new subway project; this resulted in project revision and conservation of the trees (Yan, H. \& Zhu, X. 2013) [37]. Experts and civic groups used microblogs to criticize "the regeneration project of Beijing's bell and drum tower neighborhood" proposed by local government (Lin, Y. L. et al. 2014) [27]. Planners have also recognized the potent role of new media and regarded them as a participatory platform for engaging the public in the planning process. Online forums, for instance, became an important method of public consultation during the early phase of master planning in Chaohu City (Ma, J. \& Hu, X. 2011) [28]. They enabled users not only to maintain a number of ties cheaply and easily, but to create large and diffused networks of relationships (Mandarano, 
L. et al. 2010) [29]. Weibo and online city forums have been widely used in public participation in China (nearly 97\% coverage of 300 million social media users), which provides opportunities for companies, organizations and governments (McKinsey 2012) [30]. Various levels of Chinese government opened their own official microblogs on multifunctional Weibo platform (Zhou, L. J. \& Wang, T. 2014) [39]. Government microblogs have become communication and dialogue-oriented platforms connecting public sector with the general public (Zhou, L.J. \& Wang, T. 2014) [39]. The internet and Weibo have also facilitated the engagement of experts and civic organizations in the planning process (Lin, Y.L. et al. 2014) [27].

Physical space interaction has been gradually replaced by nonphysical virtual space such as multimedia and financial markets, and long distance space interaction greatly increased (Albrechts, S. \& Mandelbaum, S. 2005) [1], But virtual space needs the support of real physical elements. But Mitchell inclined that in the 21st century, human not only live in the "reality" of cities with reinforced concrete construction, but also at the same time in a "soft" city formed by digital communication network (Shen, L. Z. 2010) [32]. But the information transmission speed in network society changed space and time limit when efficient information exchange in traditional society, the relief of which blurred the space boundaries of community.

Information distribution is no longer an absolute top-down model with a single source and direction. A real-time information exchange and a relatively more equal network structure formed based on SNSs, breaking traditional social boundaries (Mandarano, L. et al. 2010) [29].

In the social activities system built by the construction of information network, the traditional social order and material spatial relations has been disruptively struck. The virtualization of material world makes urban public space face new challenges and opportunities (Li, H. B. 2009) [25]. For the city in the process of informatization, space aesthetics of the city and architecture has break through the spatial boundaries of traditional entity, establishing interaction between real and virtual space as well as construction.

\section{RESEARCH BASIS AND NETWORK PARTICIPATION PROCESS ANALYSIS OF EVENT}

\subsection{Research purpose}

For public participation in urban planning and network society, there existed some research cases such as Dafo Temple in Guangzhou (Deng, Z. H. et al. 2014) [13], but little in network planning participation. Firstly, research scope is not wide, which concentrate on the platform with interactive, visibility such as GIS, but little in the communication platform of text with some pictures such as Weibo and posts. Secondly, Research direction is relatively single. Most studies focused only on technical parts and the interaction of the government, ignoring the actor characteristic when planning participation on Internet.

On the basis above, according the Weibo participation of Shanghai No.55 Bus line adjusting event, this research, through study on the public participation in urban planning theory and characteristics of network society, try to explore the characteristics of network planning participation and eventually reveal participation process of planning by analyzing the correlation degree between participants.

\subsection{Investigation information and network participation process}

The subject of study, No.55 Bus, although is in Shanghai, the research direction mainly concentrated in public network participation of the "No.55 Bus incident" , the collection of information data sample mainly comes from the Internet community and information publishing platform of government.

\subsubsection{Research Object}

The main research object of Shanghai No.55 Bus line adjusting event is the participants of commenting and forwarding and related Weibo forwarding from Shanghai WOW Magazine (A company located in Jing 'an district of Shanghai providing Shanghai information of culture transmission), which released a Weibo information on March 16, 2012 in Weibo platform. From then on to the last Weibo forwarding on March 30, 2012, there are 945 participants and 964 Weibo comments in total (Figure 4).

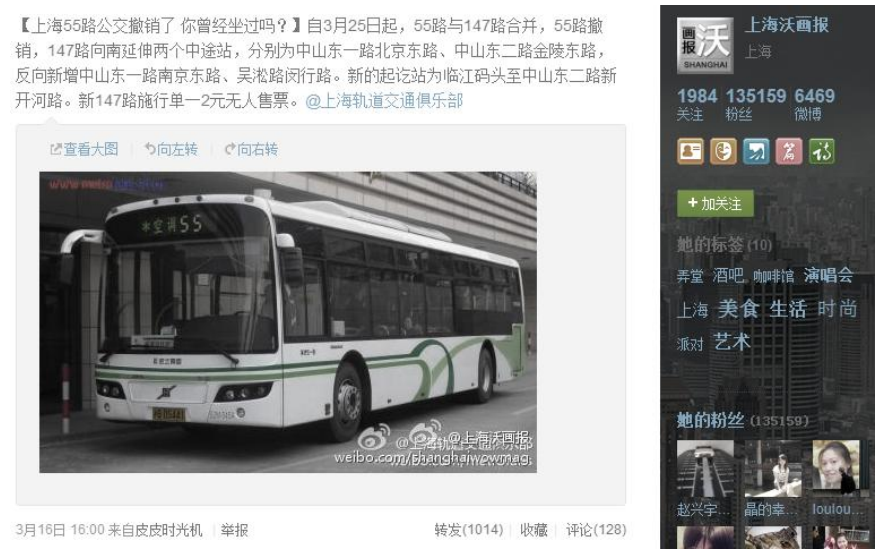

Figure 4. The Situation of Weibo comment and forwarding about Shanghai No.55 Bus line adjusting event (from Weibo.com)

\subsubsection{Event Overview}

From November 4, 2011 when Shanghai 
transportation and harbor bureau released the news on bus line adjustment to May 26, 2012 when No.910 Bus line officially changed its name to No.55 Bus line, the entire events occurred as follows:

As the development of subway transportation brings the increasing number of subway lines and stations, led to route cancelling bus routes in Shanghai every year. During this process, there are a lot of historical lines bearing the city memory disappearing including No.55 Bus line. No.55 Bus was set up on June 12, 1952, whose direction was originally from Wujiaochang to the Bund and extended to New Jiangwan city, Shiliupu later. In the decades of operation, No.55 Bus line leaves precious memories for generations of Shanghai people. While an adjustment plan of transportation and harbor bureau almost erase the memory of generations.

On March 16th of 2012,"Shanghai publishing" announced in Weibo that it would cancel No.55 Bus. At 16 o'clock, "Shanghai railway transit club" released Weibo of "cancel No.55 Bus" and caused a lot of forwarding and so by Weibo of "WOW mag". At the same time, other relevant certificated Weibo also directly released or forwarded the information. This adjustment faced a lot opposition just in a few days in Weibo. Various speech from Internet forwarding evoked a lot of people's memories and even caused the attention of some scholars thousands miles away. On 17th, Mr. Y in the planning bureau of Shanghai directly involved in Weibo by Mr. Z in Shenzhen from "WOW mag", called on positive discussion with relevant people, and directly reflected result to harbor bureau. On 18th, Mr. Y released Weibo of keeping No.55 Bus of harbor bureau. On 20th, transportation and harbor bureau formally announced that No.910 Bus will be renamed as No.55 Bus, certificated Weibo released the information and caused a new round of discussions at the same time. Then this participation event in Weibo was over, and the whole active part of process only continued for 3 days, with sporadic users as followed.

Retrospect the forward process of Weibo, we could find that, Shanghai No.55 Bus line, an inconspicuous bus line, had become a collective memory of particular urban location. In the rapid transfer of information media society, the overlap and interaction of virtual world and real world has given rise to the reconstruct of city image in particular social group.

\subsubsection{Weibo Opinion Analysis}

Due to the title of initial Weibo, Shanghai No.55 Bus dropped. The strong guidance led the main emotion in the most forward Weibo is to miss No.55 Bus bring them convenience and scenery along the way (Figure 5). After Mr. Y suggested to keep No.55 Bus, there were 96 Weibo (Figure 6) hold the same opinion in samples, among which related professionals almost chose to support, the influence incarnated. There were also 23 Weibo (Figure 6) not supporting keep No.55 Bus line. They reached consensus that it was unfair to change No.910's name to No.55 Bus. But their voices are much weaker compared with supporting voice. Besides, there is no support of professionals. There were 143 Weibo forwarding with no opinion (Figure 7), among which, they may have their own side, or support the forwarding one. They just played the role of passing information during this process. Among other Weibo, there are Weibo comments with modal particles such as $\mathrm{Ai}$, Yo, Xixi, or simple symbols and expressions such as "!". There existed dialog Weibo comments and question Weibo comments such as really? There are 160 Weibo comments like mentioned above with their unique perspective and insight as retail samples. They are not only an organic part of enriched content of Weibo, also the manifestation of decentralization of network society as well.

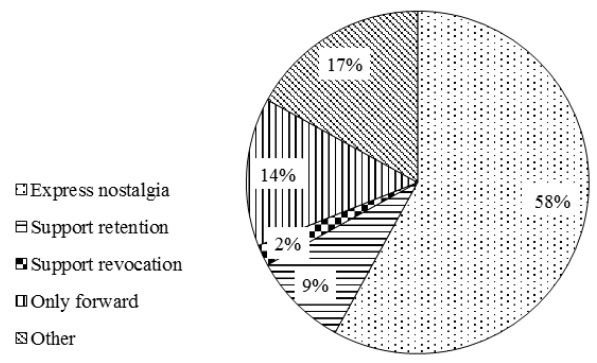

Figure 5. Weibo view sample classification proportion

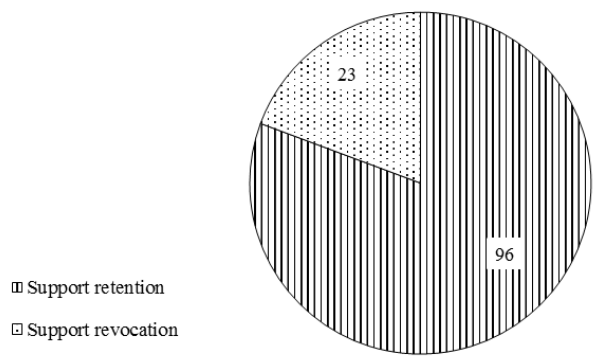

Figure 6. The No.55 Bus reserve or not vote

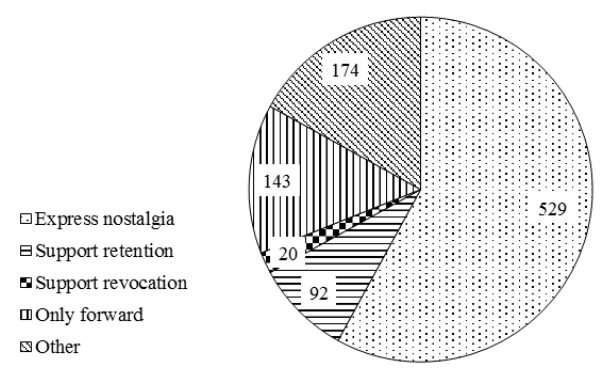

Figure 7. The statistics of Weibo view sample 


\subsubsection{Participation Pattern Analysis}

Nearly a thousand Weibo comments that research object contained provided a large number of sample data. From the overall situation of transmission, the role of $\mathrm{Mr}$. Y, as an important node, is highly significant. In this case, event information did not transmit from source Shanghai WOW Magazine to Mr. Y. From the personal attributes of transfer of key node, we can see the background of participants mostly are "Shanghai" "Planning industry" "Tongji University", among which the direct source of No.55 Bus event is Mr. Z in Shenzhen, the only participant away from Shanghai. But its non-localization node take the key function to transfer news to Mr. Y. Figure 8 reflects the spread structure of 964 research objects, from which we could obviously see that Mr. $\mathrm{Y}$ played an important role.

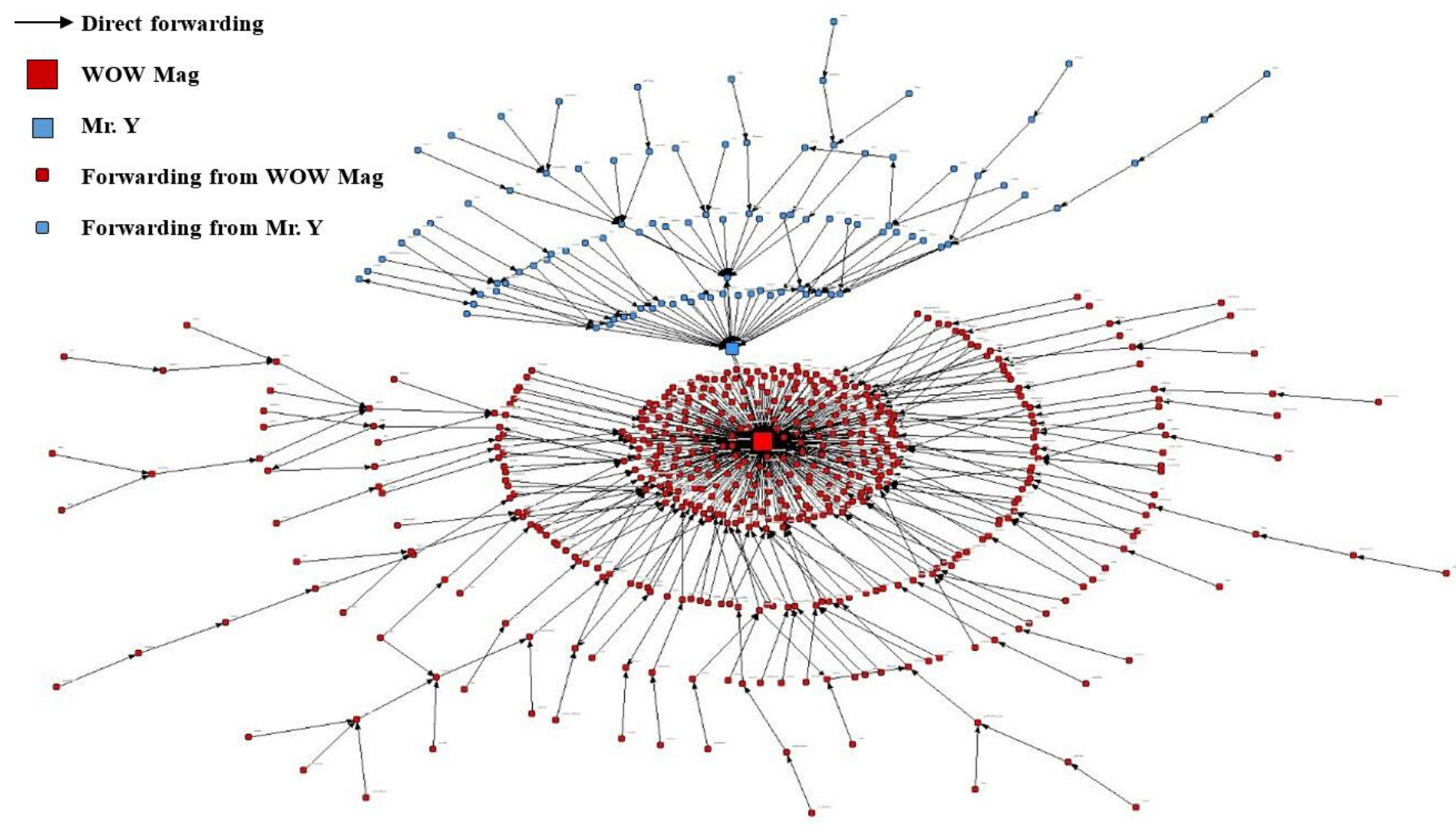

Figure 8. Weibo forwarding topology map

From forwarding number and spatial characteristic (Figure 9), we could find that transmission is fast, and the distance and affect cycle is relatively short. We could conclude from above that, transmission speed in network society changed the time and space limitation of efficient information exchange in traditional society. This relief of limitation blurred the space boundaries of community. People in different space could participate real social life through virtual internet. Meantime, because of the changes in speed of information transmission, people can get a lot of message in a short time, which cause the time people focus on the events becoming shorter and shorter. Compared with network society theory of Castells, M. (2006) [9] \& (2010) [11], the case reflects the characteristics of network society through several aspects.

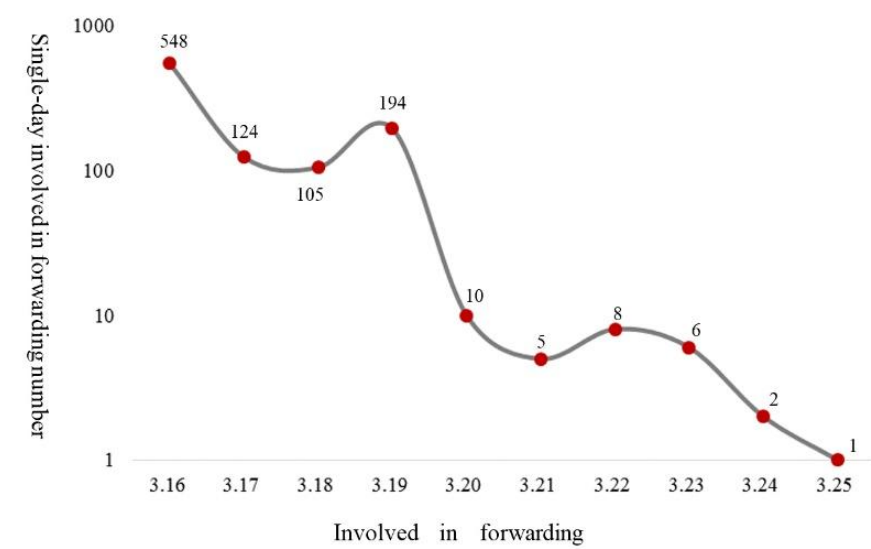

Figure 9. Weibo forwarding daily volume and temporal characteristics

(1) Weibo comments number is associated with the number of participants. Most of the participants had only one forward except Mr. Y's 4 Weibo comments. From this we find based on Weibo that the message from the microblog does not exist a key word controller, Information transmission does not through a fixed channel, but among the overlapping interwoven network system. From the perspective of 
communication study, rational opinion leaders will typically measured from two aspects in making decisions: one is their own preference, the other is constraints from public environment. In this case, there need no much explanation is that the professional background and public opinion environment prompted Mr. Y choices. It is precisely because of so many regrets and dissatisfied with revoking No.55 Bus that prompted the advice of $\mathrm{Mr}$. $\mathrm{Y}$ to put forward views through the government website who hold the background of professional planning knowledge.

(2) Spatial weakening in Weibo participation. Among 945 participants, 83.2\% come from Shanghai, the remaining $16.8 \%$ out of Shanghai, and among which majority is in Beijing and the United States (Table 1). The direct source of Mr. Z in Shenzhen, is a foreign participant out of Shanghai. This indirectly reflects time and space efficiency in information dissemination on the basis of network. From the political expression and administration, urban planning must be based on the local benefit on the space, which conflicts with network society with no geographical space characteristics. That is the conflicts with present place. Because from the perspective of the basic planning theory, direct relevance of local place is the primary factor, But nearly $20 \%$ of the nonlocal Weibo number shows "No.55 Bus event" enriches the community concept, which means the societal virtual community, who have communication and collaboration capabilities in "No.55 Bus event", in some sense is out of the constraints of geographical distances. From the point of transportation planning, this group seldom used No.55 Bus, which further shows that virtual community is clearly different from the traditional neighborhoods. The latter are really dependent on the actual users of No.55 Bus, while the former serves as a form of collective memory of the city image.

Table 1. The geographical distribution of Weibo participants

\begin{tabular}{|c|c|c|c|c|c|}
\hline Region & Users & PCT $(\%)$ & Region & Users & PCT $(\%)$ \\
\hline Shanghai & 793 & 83.30 & Japan & 5 & 0.53 \\
\hline Beijing & 28 & 2.94 & Chongqing & 4 & 0.42 \\
\hline Guangdong & 20 & 2.10 & Jiangsu & 4 & 0.42 \\
\hline America & 16 & 1.68 & Henan & 3 & 0.32 \\
\hline Australia & 8 & 0.84 & Fujian & 3 & 0.32 \\
\hline Hong Kong & 5 & 0.53 & Canada & 3 & 0.32 \\
\hline Britain & 5 & 0.53 & Other & 50 & 5.29 \\
\hline Germany & 5 & 0.53 & & & \\
\hline
\end{tabular}

(3) Clustering of the information dissemination. Take Mr. Y as node for analysis, we can clearly see a few groups of participants with the property about "planning professional" and "Tongji University".
One of the characteristics of the network society is the special group with similar property created by the virtualization, such group gathered construct a collective identity. And Programmatic identity construction refers to social actors build a new, redefine their social status based on the information from any way, and then seek a comprehensive social reform. (Castells, M. 2006) [10] In the "Shanghai No.55 Bus" event, the clustering of the participants with the property about "planning professional" and "Tongji University" is reflection of programmatic identity construction. In addition, it can be seen from figure 8, there is an obvious separated gap between the forwarding take "WOW Mag" and "Mr. Y" as the source, which also show the agglomeration above the groups with the same background in internet communication. In the "Shanghai No.55 Bus" event, the group with planning knowledge have promote public participation in the planning events and the final settlement.

(4) Information on Weibo mainly transferred by original information. After the statistics of 964 Weibo message, we can find that $88 \%$ of the Weibo message did not express views, only $12 \%$ have expressed the views retain No.55 Bus or not. However, due to the larger number of Weibo message, the number is still adequate. Judging from the number of Weibo message, single message can not form effective discussion, information mainly transfer by the original message may be due to the restriction of Weibo form.

From the behavior of participants, we can sum up the following characteristics:

(1) Participants gather spontaneously to one or several nodes. It can be seen from figure 8 , as a key node of information spread, Mr. Y brought about nearly $1 / 5$ of total forwarding on this topic. And from the statistics of Weibo message, Mr. Y released four Weibo which have triggered 151 direct or indirect forwarding. From the process of information dissemination, network messaging structure exhibits a specific central (as Mr. Y in figure 8), but in different events, the center will migrate. In Network Society, public comments without center can not effect anything. There must be some competent leaders collecting public opinions, some groups composed of elites as a bridge linking the masses and the decision-makers. Berry, L. etc. (2004) classified this as one of the defects of the network society, it is difficult for the views based on the network play an important role without effective organization and cooperation [3].

(2) Participation behavior across regions. As a discussion about a regional bus line, the phenomenon that more than $1 / 6$ of the participants come from other places do not appear in the traditional society in normal circumstances. In the traditional social model, the transaction has been limited by space boundaries, and the discussion 
usually concentrated within the region which defined by the community. The network society has broken boundaries of the community, so that the real geographical boundaries of the real world have been changed, the area living have greatly expanded through the internet. Public participation across the region has become an inevitable life mode under the background of network society.

\section{REFLECTION AND DISCUSSION}

The difference between network planning participation and traditional planning participation lies in the discrepancy of network and realistic society, thus we can conduct our reflection and discussion from these four aspects shown below:

(1) Planning participation in the network society reflects a high degree of public participation. Information dissemination methods in the network society have released the communication limits among people in time and space, and virtuality of participants' identities has eliminated the discrimination caused by gender, age, wealth, ethnic, etc. in the face-to-face communication of realistic society (Sfez, L. 2007) [31]. The communication through E-mail can have reduced the risk of the problems in the face-to-face contact as personal information exposure and quarrel in public places (Graham, S. 1999) [15]. Although those serve as the less important parts in network participation' advantages, they can make the population that avoid participating the public communication join in the discussions of city problems so as to expand the social public participation.

(2) There are some negative factors implied in the network society, such as narrow group mentality. Berry, L. etc. (2004) put forward that network society contains some problems, such as group mentality which may cause disability in objective appraisal on unusual, minority or unpopular opinions due to the pressure from the crowd, dependency on qualified leaders and effective cooperation approaches [3]. Because of the virtuality and efficiency of the network society, people can search for their interested information as they wish without being influenced by various factors in realistic society, such as barrier of traditional values in the society. Yet it makes the group that "is divided by the same type" easily come into being in the network society. Kurt • Lewin (1936) [23] hold the opinion that individual behavior, including mental activity, changed with environment conditions. Every time network collective carnival, netizens have excitement from multiplication of themselves, which is unusually strong. The excitement stimulates and promotes netizens unconsciously join into the collective consciousness and joy in it. Inside the group, there exist both the feeling of pleasure from the conformity of actions as memberships and the sense of fear from the possibility to be excluded out of the group, under the comprehensive effects of which the narrow group mentality finally forms.

From the participation group of Shanghai No.55 Bus, "Tongji University" and "Planning" have sculptured the basic boundary of virtual community. Though a success of network participation as the final resolution came out, it should be noted that whether the public opinion will change with the publishing of government expenditure on No.10 subway and No.55 bus; what are the thoughts of bus taking group of No.910 Bus, which was altered to No.55 Bus, to the bus line's name change? And from the self-criticism point of view, should No.55 Bus enjoy the privilege on account that it concerns partial route focused by professional elites? Obviously, on condition that the public opinions in network society reflect the most opinions, what $\mathrm{Mr}$. $\mathrm{Y}$ and $\mathrm{Z}$ suggested may appear different.

(3) While some utopians predict that with development of network society it will gradually replace the space in realistic society, the actual application of ICT technology should be the subtle fusion with the realistic society instead of the substitution. Graham, S. (1999) [15] pointed out that people's perception to the city in the network society still depends on the stay and movement in different spaces (room, building, street, traffic network, residence, city) based on themselves.

In the information society, the consumption generalization phenomenon that sets city image as the symbol has gradually become prominent. The consumption theory by Baudrillard, J. (2001) [2] combines consumption and symbol into one conception, among which commodity is mainly consumed and reflected as a kind of symbol. Analyzing this bus route cancellation events from dialectical point of views, the consumption generalization phenomenon that sets city image as the symbol should be reflected: As bus should be aimed at solving the transportation of residents along the route, most people joining the microblog stop using No.55 bus in real life, so should this bus routes be reserved to collect the group memory of the minority? In spite of different opinions on this discussion, it is impossible to satisfy as many symbol consumption demands by physical system of entity in the internet era with information explosion.

(4) Network participation reflects the connotation of social capital. In general, social capital includes three essential elements - relationship, trust, norm (Mandarano, L. et al. 2010) [29], which represent resources provided by human beings' status in social structure. Therefore, social capital, existing in the social structure, is invisible and makes use of cooperation among people, thus improving the efficiency and the integration of the society. In network participation, the three essential elements of 
social capital are also reflected: The first is relationship - as social capital is contained in the social group and social network, individual can not directly possess or use it, and individual can get close to and make use of the social capital only through becoming a member of the network or building network connection. The relationship in internet participation is to establish discussion relationship dominated by a certain issue through the Internet, thus playing the overall utility of social capital. The second is trust-from the human beings interaction standpoint, it can be simply defined as the trust on individuals, which means that in the presence of the opportunity to gain one's benefits by making sacrifice of the other, he or she will not do it. Trust and social relationship are closely interconnected. The former is an important dimension of the latter and is a social phenomenon that social structure is closely related to the culture (Yang, Z. F. \& Peng, S. Q. 1999) [38]. Trust is likely to be strengthened, weakened or even disappear in the relationship. Trust type depends on the type of social relationship. Trust may be either the result or the source of the relationship (Lin, J. R. 2007) [26]. Trust in network participation is established on the discussion relationship formed by common heated issues. Groups in relationship structure have a strong discussion desire of structural basic topics, thus naturally forming that trusting others to adhere to a serious and responsible attitude, and providing a powerful consciousness backing for the growth of the group voice. The third is norm-conventional norm is a kind of powerful and vulnerable social capital. It can promote specific actions, but limits the actions of others as well; It is very important to groups. It contributes to making individual behavior conducive to groups and limiting individual behavior of seeking personal interests. Therefore, the norm is also needed to be presented in network participation. The establishment of an effective and feasible norm can guarantee the network participation fair, just, scientific and effective.

\section{PROSPECT OF PLANNING PARTICIPATION IN THE NETWORK SOCIETY}

With the increasing development of information technology, internet life mode deepens in public daily life, and meanwhile the public is also increasingly concerned about the city planning and management decision related to themselves. Under this background, planning participation in the network society is more and more prominent. The government should support various kinds of network planning participation, establish sound, scientific and reasonable network planning participation platform as soon as possible, and formulate feasible regulatory norms. Meanwhile, facing the so-called "elite decision-making", government departments should have the courage to withstand the pressure, conduct field research in many places on the basis of widely listening to public opinion and carefully make decisions conforming to the actual situation, meeting the needs of most public interests and enjoying sustainable development. In addition, as public, we should actively participate in the planning discussion of network mode and express our own opinions in a rational and objective way; People with professional knowledge and reputation in the field should think about public hot topic from a more professional viewpoint, review public opinions and make objective and fair comments and decision guides.

\section{REFERENCES}

[1] Albrechts, S. \& Mandelbaum, S. 2005. The network society: a new context for planning. London: Routledge.

[2] Baudrillard, J. (Liu, C. F. \& Quan, Z. G. interpret) 2001. Consumer Society. China: Nanjing University Press.

[3] Berry, L. 2004. The Collaborative Organization: Leadership Lessons from Mayo Clinic. Organizational Dynamics 33(3): 228-242.

[4] Booher, D. \& Innes, J. 2002. Network power in collaborative planning. Journal of planning education and research 21(3): 221-236.

[5] Boyd, D. M. \& Ellison, N. B. 2007. Social network sites: Definition, history, and scholarship. Journal of ComputerMediated Communication 13(1): 210-230.

[6] Castells, M. 1989. The informational city: Information technology, economic restructuring, and the urbanregional process. Basil Blackwell Oxford.

[7] Castells, M.1996. The rise of the network society: The information age: Economy, society and culture, Volume 1. Oxford: Blackwell.

[8] Castells, M. 2005.Globalization, Desarrolloy Democracia: Chileen el Contexto Mundia. San Diego: Fondo de Cultura Economica.

[9] Castells, M. 2006. The Network Society-A Cross-cultural Perspective. Cheltenham: Edward Elgar.

[10] Castells, M. 2006. The Power of Identity. China: Social sciences academic press.

[11] Castells, M. 2010.Globalisation, Networking, Urbanisation: Reflections on the Spatial Dynamics of the information Age. Urban Studies 47(13) 2737-2745.

[12] Cheng, Y. 2013. Collaborative planning in the network: Consensus seeking in urban planning issues on the Internet - the case of China. Planning Theory 12(4):351368.

[13] Deng, Z. H., Wang, S. F., \& Zhao, M. X. 2014. Public participation in planning through new media and prospects: a case study on Dafo Temple expansion, Guangzhou. Urban planning 38(7):84-90.

[14] Gordon, E. \& Manosevitch, E. 2011. Augmented deliberation: Merging physical and virtual interaction to engage communities in urban planning. New Media \& Society 13(1):75 -95.

[15] Graham, S. \& Marvin, S. 1999. Planning Cyber-Cities? Integrating Telecommunications into Urban Planning. Town Planning Review 70(1):89-114. 
[16] Graham, S. 2005. Strategies for Networked Cities. In Louis Albrechts and Seymour J. Mandelbaum (ed.), The Network Society. UK: Routledge. 95-110.

[17] Healey, P. 1997. An institutionalist approach to spatial planning. In P. Healey, A. Khakee, A. Motte \& B. Needham (ed.), Making strategic spatial polans: innovation in Europe. London: UCL Press.

[18] Healey, P. 1997. Collaborative planning: Shaping places in fragmented societies. London: Macmillan.

[19] Healey, P. 2003. Collaborative Planning in Perspective. Planning Theory 2(2):101-123.

[20] Innes, J. E. \& D. E. Booher. 2010. Planning with Complexity: An Introduction to Collaborative Rationality for Public Policy (1st ed.). London: Routledge.

[21] Judith E. Innes. \& David E. Booher. 1999. Consensus Building as Role Playing and Bricolage. Journal of the American Planning Association 65:1, 9-26.

[22] Kaneyasu, I. 1997. Requirement-consciousness towards the urban infrastructure in the information society. City Planning Review 46(5): 25-28.

[23] Kurt - Lewin. 1936. The Principle of Topological. New York: McGraw-Hill B. C.

[24] Leaf, M. \& Hou, L. 2006. The "third spring" of urban planning in China: The resurrection of professional planning in the post-Mao era. China Information 20(3): 553-585.

[25] Li, H. B. 2009. Digital interface design combined with Urban public space. Master Thesis of Tongji University.

[26] Lin, J. R. 2007. From discourse analysis to reflexivity-a new developmental trend of Scientific Sociology. Journal of dialectics of nature 29(2):55-61.

[27] Lin, Y. L., Zhang, X. L. \& Geertman, S. 2014. Toward smart Governance and social sustainability for Chinese migrant communities. Journal of Cleaner Production. (resubmitted)

[28] Ma, J. \& Hu, X. 2011. Public consultation during prophase of master planning: Practice and exploration: A case of Chaohu City (in Chinese). Urban Studies 18(2):13.

[29] Mandarano, L., Meenar, M. \& Steins, C.2010. Building social capital in the digital age of civic engagement. Journal of Planning Literature 25(2):123-135.

[30] McKinsey 2012. There are 300 million social media users in China! http://tech.qq.com/a/20120426/0000023.htm (accessed 2 February 2013).

[31] Sfez, L. (Zhu, Z. M. interpret) 2007. Communication. Beijing: Communication University of China press.

[32] Shen, L. Z. 2010. Flowing space.Nanjing: Southeast University Press.

[33] Shiode, N. 1999. Visualising the spatial pattern of Internet address space. In B.M.Gittings (ed.), Innovations in GIS 6: Integrating Information Infrastructure with Geographical Information. UK.

[34] Scott Dempwolf \& L. Ward Lyles.2012.Uses of Social Ne twork Analysis in Planning: A Review of the Literature. $J$ ournal of Planning Literature 2(27):3-21.

[35] Verma, N. \& Shin, H. 2006. Communicative Action and the NETwork Society: A Pragmatic Marriage?In Louis Albrechts and Seymour J.Mandelbaum (ed.), The Network Society.UK: Routledge,9-24.

[36] Voets, J., Dezeure K \& De Rynck, F. 2007. Collaborative roles of public officials in urban planning processes: an exploration. ISoCaRP Congress: 43.

[37] Yan, H. \& Zhu, X. 2013. Chinese planning participation in new media age: A case-study of Nanjing phoenix tree event (in Chinese). Shaanxi Journal of Agricultural Sciences 59(3): 211-214.

[38] Yang, Z. F. \& Peng, S. Q. 1999. The conceptualization of Chinese interpersonal relationships: a view of interpersonal relationships. Sociological Studies 2:1-21.

[39] Zhou, L. J. \& Wang, T. 2014. Social media: A new vehicle for city marketing in China. Cities 37:27-3. 